\title{
Toll-like receptor ligands induce the expression of interferon-gamma and interleukin-17 in chicken CD4+ T cells
}

\author{
Michael St. Paul, Neda Barjesteh, Sarah Paolucci, Yanlong Pei and Shayan Sharif*
}

\begin{abstract}
Background: Toll-like receptors (TLRs) are evolutionarily conserved pattern recognition receptors that mediate host responses to pathogens. To date, at least 10 different TLRs have been identified in chickens including TLR2, which binds lipopeptides and other similar ligands such as Pam3CSK4, TLR3, which binds double stranded RNA as well as synthetic molecules such as poly I:C, TLR4, which binds lipopolysaccharide (LPS), and TLR21, which binds CpG DNA motifs. In mammals, TLRs have been detected on CD4+ T cells where they mediate cellular survival, proliferation and the production of cytokines. However, the TLR-mediated responses in chicken CD4+ T cells remain to be determined. As such, the objective of the present study was to elucidate the kinetics of cytokine response to several different TLR ligands in chicken CD4+ T cells.

Results: The results suggest that these cells express TLRs 2, 3, 4 and 21 at the transcript level, and treatment with ligands for these TLRs significantly influenced the expression of the cytokines interferon (IFN)- $\gamma$ and interleukin (IL)-17, but not IL-4, IL-10 and IL-13. Specifically, treatment with Pam3CSK4, poly I:C and LPS up-regulated IFN- $y$ transcripts, while CPG ODN significantly down-regulated them. In contrast, at least one dose of each of the TLR ligands, except for Pam3CSK4, significantly down-regulated IL-17 transcripts.
\end{abstract}

Conclusion: Chicken CD4+ T cells respond to ligands for TLRs 2, 3, 4 and 21 by up-regulating or down-regulating cytokine transcripts. Future studies may consider exploring how these TLR ligands may modulate other effector functions in chicken CD4+ T cells, as well as in other T cell subsets such as CD8+ T cells.

Keywords: Chicken, T cell, Toll-like receptor, Interferon- $\gamma$, Interleukin-17, CD4+ T-helper, Pam3CSK4, Poly I:C, LPS, $\mathrm{CPG}$

\section{Background}

Toll-like receptors (TLRs) are evolutionarily conserved pattern recognition receptors that bind conserved motifs on pathogens termed pathogen associated molecular patterns (PAMPs) [1]. To date, at least 10 different TLRs have been identified in chickens including TLR2, which binds lipopeptides (e.g. Pam3CSK4) and other similar ligands, TLR3, which binds double stranded RNA (e.g. poly I:C), TLR4, which binds lipopolysaccharide (LPS), and TLR21, which binds CpG DNA motifs [2]. Toll-like receptors have been detected in several cell subsets including in macrophages, heterophils and B cells [3].

\footnotetext{
* Correspondence: shayan@uoguelph.ca

Department of Pathobiology, Ontario Veterinary College, University of Guelph, Guelph, Ontario N1G 2W1, Canada
}

Interactions between TLRs and their ligands typically results in cellular activation, enhanced effector functions and the production of cytokines. In the case of mammalian T cells, TLR stimulation promotes cell proliferation and survival as well as induction of cytokines, such as interferon (IFN) $\gamma$ [4-7]. In addition, TLR stimulation may also promote the differentiation of naïve $\mathrm{CD} 4+\mathrm{T}$ cells into one of the many different T-helper $\left(\mathrm{T}_{\mathrm{H}}\right)$ cell subsets [8]. To date, several different TLRs have been detected in mammalian CD4+ T cells [9].

Although well documented in mammals, the TLRmediated responses in chicken $\mathrm{T}$ cells have yet to be elucidated. So far, a few TLRs have been identified in chicken CD4+ T cells including TLRs 2, 3 and 4 [3]. However, the full repertoire of TLRs expressed in chicken CD4+ T cells and their responses to TLR ligands have yet to be 
characterized. To this end we hypothesized that chicken $\mathrm{T}$ cells express TLRs and respond to TLR ligands by upregulating cytokine transcripts. As such, the objective of the present study was to examine the kinetics of the TLRmediated cytokine response in chicken CD4+ T cells. The results suggest that CD4+ T cells express TLRs 2, 3, 4 and 21 at the transcript level, and treatment with ligands for these TLRs significantly influenced the expression of the cytokines IFN- $\gamma$ and interleukin (IL)-17, but not IL-4, IL10 and IL-13.

\section{Results and discussion}

Toll-like receptor ligands have previously been shown to modulate the production of cytokines in several chicken cell subsets, including in macrophages, heterophils and $B$ cells [10-12]. Here, we show that a similar phenomenon may be extended to chicken CD4+ T cells.

In mammals, $\mathrm{CD} 4+\mathrm{T}$ cells may be classified into several different subsets such as $\mathrm{T}_{\mathrm{H}} 1, \mathrm{~T}_{\mathrm{H}} 2, \mathrm{~T}_{\mathrm{H}} 17$ and regulatory $\mathrm{T}$ cells $\left(\mathrm{T}_{\mathrm{REG}}\right)$ [13]. In addition to producing a distinct profile of cytokines and performing different effector functions, each cell subset also expresses a different repertoire of TLRs. For example, TLR10 has been detected in human regulatory $\mathrm{T}$ cells, but not in non-regulatory CD4+ T cells [14]. Nevertheless, CD4+ T cells, in general, express transcripts for TLRs 2, 3, 4, 5, 7/8 and 9 in both mice and humans [9]. In chicken CD4+ T cells, it was shown that they also express TLRs transcripts including those for TLRs 2, 3 and 4 [3]. However, the study by Iqbal et al., (2005) used semi-quantitative PCR and as such, we employed real-time PCR to provide a more accurate quantification of TLR transcript levels (Figure 1). Our results suggest chicken CD4+ T cells express TLRs 2, 3, 4 and 21 at the transcript level, and not TLRs 5 and 7. Moreover, transcripts for TLR2 were the most abundant, followed by transcripts for TLR3 and lastly by TLRs 4 and 21 . This therefore raises the possibility that chicken CD4+ $\mathrm{T}$ cells may have the potential to

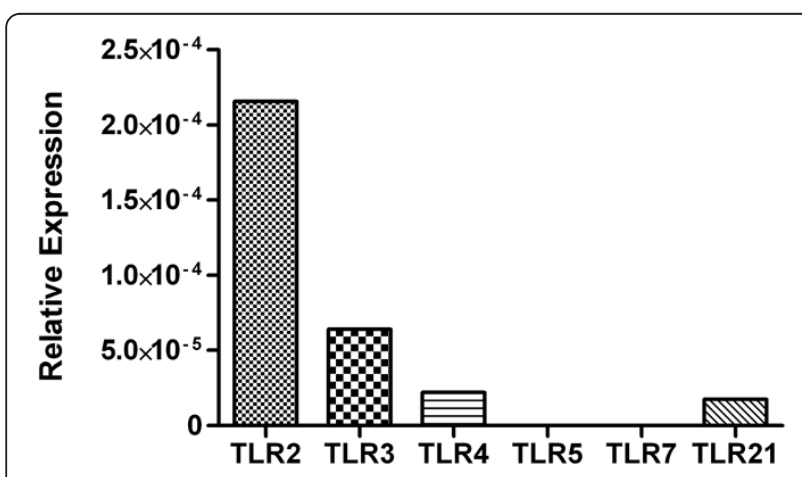

Figure 1 TLR expression in chicken CD4+ T cells. Gene expression of TLR transcripts in un-stimulated chicken CD4+ T cells relative to the house-keeping gene $\beta$-actin. respond directly to PAMPs derived from both viral and bacterial pathogens.

Different mammalian CD4+ cell subsets produce a distinct profile of cytokines upon stimulation. These cytokines include IFN- $\gamma$, which is produced by $\mathrm{T}_{\mathrm{H}} 1$ cells and IL-4/13 which are produced by $\mathrm{T}_{\mathrm{H}} 2$ cells, as well as IL-17 and IL-10, which are produced by $\mathrm{T}_{\mathrm{H}} 17$ cells and $\mathrm{T}_{\text {REGS}}$, respectively. Although in chickens it is not yet known if such CD4+ T cell subsets exist, evidence accumulated over the last few years raises the possibility that at least some of these subsets might [15-17]. As such, in the present study, we examined the above cytokines to determine how TLR ligands modulate their expression (Figures 2 and 3).

In mammals, TLR2 ligands such as Pam3CSK4 have been shown to directly activate CD4+ T cells and induce their production of IFN- $\gamma$, in the absence of $\mathrm{T}$ cell receptor (TCR) signaling [5,7]. Our results suggest that this may also be the case in chicken CD4+ T cells, as treatment with Pam3CSK4 significantly up-regulated IFN- $\gamma$ transcripts at $3(\mathrm{p} \leq 0.01)$ and $8(\mathrm{p} \leq 0.01)$ hours posttreatment (Figure 2). This effect was not limited only to Pam3CSK4, as both poly I:C ( $\leq 0.01)$ and LPS ( $\mathrm{p} \leq 0.05)$ significantly enhanced IFN $-\gamma$ transcripts levels as well (Figure 2). This is in contrast to what occurs in mammals, as poly I:C and LPS fail to directly up-regulate IFN- $\gamma$ production in $\mathrm{T}_{\mathrm{H}} 1$ cells [7]. In fact, when combined with TCR stimulation, LPS inhibits IFN- $\gamma$ production in mammalian $\mathrm{T}$ cells, which was shown to be mediated by the TIR-domain-containing adapterinducing interferon- $\beta$ (TRIF) pathway [18]. In chickens, emerging evidence suggests that both TLRs 3 and 4 signal through the TRIF pathway as indicated by a robust type I IFN response following treatment with these ligands [19-21]. However, as these ligands both upregulated IFN- $\gamma$ transcripts in the present study, this raises the possibility that there might be some differences between the chicken and mammalian TRIF pathways, potentially with respect to the accessory and signaling molecules involved. As such, future studies should be aimed at further elucidating the mechanisms involved in the TRIF signaling pathway in chickens.

We discovered that there was a significant downregulation (controls were set to 1 ) of IFN- $\gamma$ transcripts following treatment CpG ODN at 1 (p $\leq 0.01)$ and 8 $(\mathrm{p} \leq 0.05)$ hours post-treatment (Figure 2). This is in contrast with what has been shown in mammalian CD4+ $T$ cells, because CpG ODN enhances production of cytokines such as IL-2 and IFN- $\gamma$ by these cells [22]. However, this enhanced cytokine production occurs only in conjunction with TCR signaling, and as such, future studies may consider exploring whether adding antichicken CD3 may alter the responses to $\mathrm{CpG}$ ODN and other TLR ligands. 


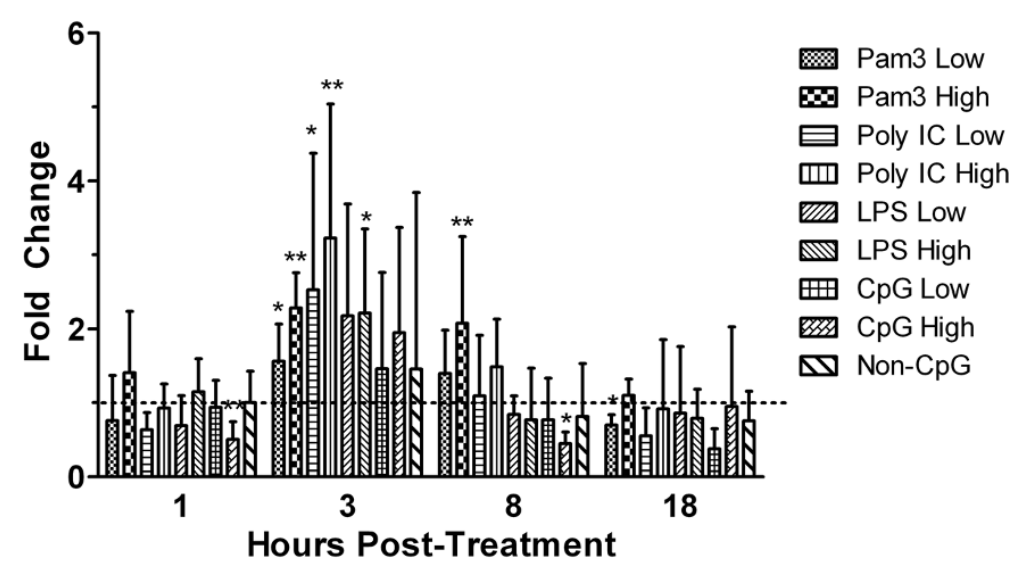

Figure 2 Gene expression of IFN- $\gamma$. Relative gene expression of IFN- $\gamma$ in chicken CD4+ T cells at 1, 3, 8 and 18 hours post-treatment with low $(1 \mu \mathrm{g} / \mathrm{mL})$ and high $(5 \mu \mathrm{g} / \mathrm{mL})$ doses of the TLR ligands Pam3CSK4, LPS and CpG ODN, or with a low $(10 \mu \mathrm{g} / \mathrm{mL})$ or high $(50 \mu \mathrm{g} / \mathrm{mL}) \mathrm{dose}$ of poly I: C. Graphed data represent mean fold change of 4 treatment replicates compared to the medium control group \pm standard error. Results were considered statistically significant from the medium-treated control group if $p \leq 0.05\left(^{*}\right)$ and $p \leq 0.01\left(^{* *}\right)$.

In addition to enhancing IFN- $\gamma$ production, TLR ligands may also modulate responses of other $\mathrm{T}$ cell subsets, such as $\mathrm{T}_{\mathrm{H}} 17$ cells. For example, treatment of naïve CD4+ $\mathrm{T}$ cells with Pam3CSK4 promotes their differentiation into $\mathrm{T}_{\mathrm{H}} 17$ cells [8]. Importantly, when fully differentiated $\mathrm{T}_{\mathrm{H}} 17$ cells are treated with TLR ligands including Pam3CSK4 and LPS, but not poly I:C, a significant increase in IL-17 production is observed [8]. However, this does not appear to be the case in chickens, as suggested by our results (Figure 3 ). We found that both poly I:C, and the high dose of CpG ODN ( $\mathrm{p} \leq 0.01)$ significantly down-regulated IL-17 transcripts at 1 hour and 8 hours post-treatment, respectively. Moreover, we found that treatment with the low dose of LPS significantly down-regulated IL-17 transcripts at 1 hour posttreatment ( $\mathrm{p} \leq 0.01$ ), while the high dose significantly up-regulated IL-17 at 1 hour post-treatment ( $\mathrm{p} \leq 0.05$ ). Although the reason behind this observation is not known, we have observed a similar down-regulation of murine natural killer T (NKT) cell activities in response to some TLR ligands, including CPG ODN, which we have attributed to a TLR-mediated increase in dual specific protein phosphatases (DUSPs) (Villanueva et al., unpublished data). As such, future studies may consider employing additional assays in order to examine the role of DUSPs in chicken TLR mediated responses.

In mammals, evidence suggests that $\mathrm{T}_{\mathrm{H}} 2$ cells are non-responsive to TLR ligands and fail to become activated and up-regulate the production of IL-4 [7]. This seems to also be the case in chickens, as we did not detect any significant up-regulation of IL-4 or IL-13 in

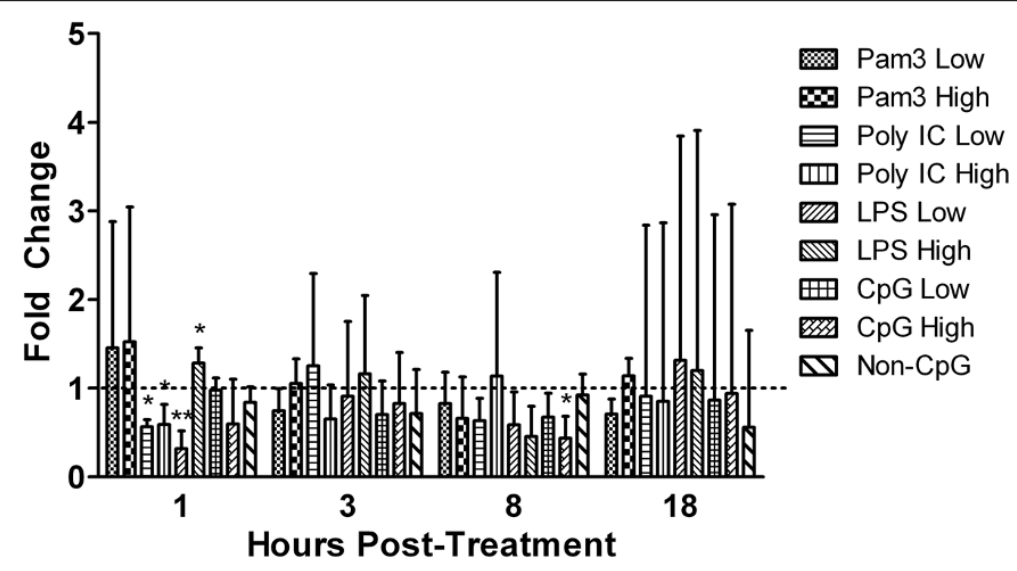

Figure 3 Gene expression of IL-17. Relative gene expression of IL-17 in chicken CD4+ T cells at 1, 3, 8 and 18 hours post-treatment with low $(1 \mu \mathrm{g} / \mathrm{mL})$ and high $(5 \mu \mathrm{g} / \mathrm{mL})$ doses of the TLR ligands Pam3CSK4, LPS and CpG ODN, or with a low $(10 \mu \mathrm{g} / \mathrm{mL})$ or high $(50 \mu \mathrm{g} / \mathrm{mL})$ dose of poly I:C. Graphed data represent mean fold change of 4 treatment replicates compared to the medium control group \pm standard error. Results were considered statistically significant from the medium-treated control group if $p \leq 0.05\left(^{*}\right)$ and $p \leq 0.01\left(^{* *}\right)$. 
Table 1 Primer sequences and accession numbers used for real-time PCR

\begin{tabular}{|c|c|c|}
\hline Target gene & Primer sequence & Accession number \\
\hline \multirow[t]{2}{*}{ TLR2 } & F: 5'- ATCCTGCTGGAGCCCATTCAGAG -3' & [GenBank: NM_204278.1/NM_001161650] \\
\hline & $\overline{R:} 5^{\prime}-$ TTGCTCTTCATCAGGAGGCCACTC - -3' & \\
\hline \multirow[t]{2}{*}{ TLR3 } & F: 5'- TCAGTACATTTGTAACACCCCGCC - $3^{\prime}$ & [GenBank: DQ780341] \\
\hline & R: 5'- GGCGTCATAATCAAACACTCC -3' & \\
\hline \multirow[t]{2}{*}{ TLR4 } & F: 5'- TGCCATCCCAACCCAACCACAG -3' & [GenBank: AY064697.1] \\
\hline & R: 5'- ACACCCACTGAGCAGCACCAA -3' & \\
\hline \multirow[t]{2}{*}{ TLR5 } & F: 5'- TTCTTGCAACCTCACAGGTGTTCC -3' & [GenBank: NM_001024586.1] \\
\hline & R: 5'- CAGGTCCAAGACACGAAGATT -3' & \\
\hline \multirow[t]{2}{*}{ TLR7 } & F: 5'- TTCTGGCCACAGATGTGACC -3' & [GenBank: NM_001011688] \\
\hline & R: 5'- CCTTCAACTTGGCAGTGCAG -3' & \\
\hline \multirow[t]{2}{*}{ TLR21 } & F: 5'- CCTGCGCAAGTGTCCGCTCA -3' & [GenBank: AJ720600.1] \\
\hline & R: 5'- GCCCCAGGTCCAGGAAGCAG -3' & \\
\hline \multirow[t]{2}{*}{$\mathrm{IFN}-\gamma$} & F: 5'- ACACTGACAAGTCAAAGCCGCACA-3' & [GenBank: X99774] \\
\hline & R: 5'-AGTCGTTCATCGGGAGCTTGGC-3' & \\
\hline \multirow[t]{2}{*}{$\overline{I L}-4$} & F: 5'-TGTGCCCACGCTGTGCTTACA-3' & [GenBank: AJ621249.1] \\
\hline & R: 5'- CTTGTGGCAGTGCTGGCTCTCC-3' & \\
\hline \multirow[t]{2}{*}{ IL-10 } & F: 5'- AGCAGATCAAGGAGACGTTC -3' & [GenBank: AJ621614] \\
\hline & R: 5'- ATCAGCAGGTACTCCTCGAT -3 & \\
\hline \multirow[t]{2}{*}{ IL-13 } & F: 5'- ACTTGTCCAAGCTGAAGCTGTC -3' & [GenBank: AJ621250] \\
\hline & R: 5'- TCTTGCAGTCGGTCATGTTGTC -3' & \\
\hline \multirow[t]{2}{*}{ IL-17 } & F: 5'- CACTGCTGTTGGTGTTGCT -3' & [GenBank: AJ493595] \\
\hline & R: 5'- TCAGCAACCAAGCGGGGG -3' & \\
\hline \multirow[t]{2}{*}{$\overline{\beta-A c t i n}$} & F: 5'-CAACACAGTGCTGTCTGGTGGTA-3' & [GenBank: X00182] \\
\hline & R: 5'-ATCGTACTCCTGCTTGCTGATCC-3' & \\
\hline
\end{tabular}

response to any of the TLR ligand treatments (data not shown). In addition, we also did not detect any significant up-regulation of IL-10 either in response to Pam3CSK4 or any of the other TLR ligands (data not shown). Although in mammals IL-10 may be produced by $\mathrm{T}_{\mathrm{H}} 2$ cells as well as $\mathrm{T}_{\mathrm{REGS}}$, in chickens, evidence suggests that stimulated $\mathrm{CD} 4+\mathrm{CD} 25+$ regulatory $\mathrm{T}$ cells are the predominant source of IL-10, as they produce more than 30 times the amount of IL-10 when compared against stimulated CD4+ CD25- T cells [15]. Nevertheless, TLR ligands have been shown to directly activate mammalian $\mathrm{T}_{\text {REGS }}$ and promote their proliferation and survival, however this occurred only in conjunction with TCR stimulation [4]. Therefore, we speculate that this lack of up-regulation in the chicken CD4+ T cells may be due to lack of TCR stimulation. However, there are a few other possible explanations that could be considered. For example, i) chicken $\mathrm{T}_{\text {REGS }}$ may not respond to TLR ligands or ii) our $\mathrm{T}$ cell population may potentially be limited in its diversity and may have an oligoclonal or monoclonal nature. As a result, the population of $\mathrm{T}$ cells that we have used in the present study might have been devoid of $\mathrm{T}_{\mathrm{H} 2}$ and $\mathrm{T}_{\mathrm{REG}}$ populations.

\section{Conclusions}

In conclusion, we have shown that chicken CD4+ T cells express several TLRs at the transcript level and respond to treatment with TLR ligands by modulating the expression of IFN- $\gamma$ and IL-17 transcripts, but not IL-4, IL-10 or IL-13. Future studies may consider exploring how these TLR ligands may modulate other effector functions in chicken CD4+ T cells, as well as in other $\mathrm{T}$ cell subsets such as CD8+ T cells.

\section{Methods \\ TLR ligands}

Pam3CSK4 was purchased from Invivogen (Burlington, ON), poly I:C and LPS from Escherichia coli 0111:B4 were purchased from Sigma-Aldrich-Canada (Oakville, ON), while synthetic class B CpG ODN 2007 [5'- TC GTCGTTGTCGTTTTGTCGTT-3'] and non-CpG ODN [5'- TGCTGCTTGTGCTTTTGTGCTT-3'] were purchased from Eurofins MWG Operon (Ebersberg, GER). All of the ligands used were re-suspended in sterile water or phosphate buffered saline (PBS, $\mathrm{pH}$ 7.4) and diluted to working concentrations in complete RPMI medium. 


\section{Stimulation of T cells with TLR ligands}

Reticuloendotheliosis virus transformed CD4+ T cells were generated using the protocol previously described for transforming chicken B cells [23], with slight modifications. In the present study, mononuclear splenocytes from 1 week-old chickens were used as the starting cell population. After transformation, the cells were passaged several times, leading to elimination of non-transformed cells. Subsequently, purity of the transformed cells was assessed using flow cytometry. T cells were then cultured in RPMI-1640 (Invitrogen, Burlington, ON) supplemented with $10 \%$ heat-inactivated fetal bovine serum, $200 \mathrm{U} / \mathrm{mL}$ penicillin, $80 \mu \mathrm{g} / \mathrm{mL}$ streptomycin, $25 \mathrm{mg}$ gentamicin, $10 \mathrm{mM}$ HEPES buffer, $50 \mu \mathrm{M} \beta-$ mercaptoethanol, and $2 \mathrm{mM}$ L-glutamine, and seeded into 48 -well plates at $1 \times 10^{7}$ cells $/ \mathrm{mL}$ for in vitro stimulation with either a low $(1 \mu \mathrm{g} / \mathrm{mL})$ or high $(5 \mu \mathrm{g} / \mathrm{mL})$ dose of each TLR ligand, except for poly I:C, which was delivered at $10 \mu \mathrm{g} / \mathrm{mL}$ or $50 \mu \mathrm{g} / \mathrm{mL}$, respectively. The control groups received non-CpG ODN $(5 \mu \mathrm{g} / \mathrm{mL})$ or medium. Cells were harvested at $1,3,8$ and 18 hours poststimulation for RNA extraction.

\section{RNA extraction and CDNA synthesis}

Total RNA was extracted from $\mathrm{T}$ cells using TRIzol ${ }^{\circledR}$ (Invitrogen, Carlsbad, CA) according to the manufacturer's protocol and treated with DNA Free ${ }^{\circledR}$ (Ambion, Austin, TX) DNAse. Subsequently, $1 \mu$ g of purified RNA was reverse transcribed to cDNA using Superscript ${ }^{\circledR}$ II First Strand Synthesis kit (Invitrogen, Carlsbad, CA) and oligo-dT primers, according to the manufacturers recommended protocol. The resulting cDNA was subsequently diluted 1:10 in DEPC treated water.

\section{Real-time PCR}

Quantitative real-time PCR using SYBR Green was performed on diluted cDNA using the LightCycler ${ }^{\circledR} 480$ II (Roche Diagnostics GmbH, Mannheim, GER) as previously described [19]. Briefly, each reaction involved a pre-incubation at $95^{\circ} \mathrm{C}$ for $10 \mathrm{~min}$, followed by 45 cycles of $95^{\circ} \mathrm{C}$ for $10 \mathrm{~min}, 55^{\circ} \mathrm{C}-64^{\circ} \mathrm{C}\left(\mathrm{T}_{\mathrm{A}}\right.$ as per primer) for $5 \mathrm{~s}$, and elongation at $72^{\circ} \mathrm{C}$ for $10 \mathrm{~s}$. Subsequent melt curve analysis was performed by heating to $95^{\circ} \mathrm{C}$ for $10 \mathrm{~s}$, cooling to $65^{\circ} \mathrm{C}$ for $1 \mathrm{~min}$, and heating to $97^{\circ} \mathrm{C}$. Primers were synthesized by Sigma-Aldrich-Canada (Oakville, $\mathrm{ON})$, and their specific sequences and accession numbers are outlined in Table 1.

\section{Data analysis}

Relative expression levels of all genes was calculated relative to the housekeeping gene $\beta$-actin using the LightCycler ${ }^{\circledR} 480$ Software (Roche Diagnostics GmbH, Mannheim, GER), based on the formula developed by Pfaffl [24]. Data represent mean fold change of 4 replicates compared to the medium control group \pm standard error. The transcript levels in the mediumtreated control group were set to 1 . Results were considered statistically significant from the medium-control group if $\mathrm{p} \leq 0.05\left(^{*}\right)$ and $\mathrm{p} \leq 0.01{ }^{(* *)}$. Fold changes, standard error and statistical significance were calculated using the software REST 2009 (Qiagen, Valencia, CA) [25].

\section{Abbreviations}

TLR: Toll-like receptor; LPS: Lipopolysaccharide; ODN: Oligodeoxynucleotides; IFN: Interferon; L: Interleukin; CD: Cluster of differentiation; PAMPs: Pathogen associated molecular patterns; $T_{H}$ : T-helper; TCR: T cell receptor; NKT: Natural killer T cell; DUSPs: Dual specific protein phosphatases.

\section{Competing interests}

The authors declare that they have no competing interests.

\section{Authors' contributions}

MSP designed and conducted the experiment, processed the samples, analyzed the results and drafted the manuscript. NB, SP and YP assisted with conducting the experiment, processing the samples and revising the manuscript. SS assisted with designing the experiment and drafting and revising the manuscript. All authors have read and approved the final manuscript.

\section{Acknowledgements}

Michael St. Paul is a recipient of an Ontario Graduate Scholarship in Science and Technology. This work was funded by Natural Sciences and Engineering Research Council of Canada, Poultry Industry Council, and OMAFRA.

Received: 13 August 2012 Accepted: 30 October 2012

Published: 1 November 2012

\section{References}

1. Medzhitov R: Toll-like receptors and innate immunity. Nat Rev Immunol 2001, 1:135-145.

2. Brownlie R, Allan B: Avian toll-like receptors. Cell Tissue Res 2011, 343:121-130.

3. Iqbal M, Philbin VJ, Smith AL: Expression patterns of chicken toll-like receptor mRNA in tissues, immune cell subsets and cell lines. Vet Immunol Immunopathol 2005, 104:117-127.

4. Chen Q, Davidson TS, Huter EN, Shevach EM: Engagement of TLR2 does not reverse the suppressor function of mouse regulatory $T$ cells, but promotes their survival. J Immunol 2009, 183:4458-4466.

5. Caron G, Duluc D, Frémaux I, Jeannin P, David C, Gascan H, Delneste Y: Direct stimulation of human T cells via TLR5 and TLR7/8: flagellin and R-848 up-regulate proliferation and IFN-gamma production by memory CD4+ T cells. J Immunol 2005, 175:1551-1557.

6. Gelman AE, Zhang J, Choi Y, Turka LA: Toll-like receptor ligands directly promote activated CD4+ T cell survival. J Immunol 2004, 172:6065-6073.

7. Imanishi T, Hara H, Suzuki S, Suzuki N, Akira S, Saito T: Cutting edge: TLR2 directly triggers Th1 effector functions. J Immunol 2007, 178:6715-6719.

8. Reynolds JM, Pappu BP, Peng J, Martinez GJ, Zhang Y, Chung Y, Ma L, Yang $X \mathrm{O}$, Nurieva RI, Tian Q, Dong C: Toll-like receptor 2 signaling in CD4 (+) T lymphocytes promotes $T$ helper 17 responses and regulates the pathogenesis of autoimmune disease. Immunity 2010, 32:692-702.

9. Kulkarni R, Behboudi S, Sharif S: Insights into the role of Toll-like receptors in modulation of T cell responses. Cell Tissue Res 2011, 343:141-152.

10. St Paul M, Paolucci S, Read LR, Sharif S: Characterization of responses elicited by toll-like receptor agonists in cells of the bursa of fabricius in chickens. Vet Immunol Immunopathol 2012, 149:237-244.

11. Kogut MH, lqbal M, He H, Philbin V, Kaiser P, Smith A: Expression and function of toll-like receptors in chicken heterophils. Dev Comp Immunol 2005, 29:791-807.

12. He H, Crippen TL, Farnell MB, Kogut MH: Identification of CpG oligodeoxynucleotide motifs that stimulate nitric oxide and cytokine 
production in avian macrophage and peripheral blood mononuclear cells. Dev Comp Immunol 2003, 27:621-627.

13. Zhu J, Paul WE: CD4 T cells: fates, functions, and faults. Blood 2008, 112:1557-1569

14. Bell MP, Svingen PA, Rahman MK, Xiong Y, Faubion WA: FOXP3 regulates TLR10 expression in human T regulatory cells. J Immunol 2007, 179:1893-1900.

15. Shanmugasundaram R, Selvaraj RK: Regulatory $T$ cell properties of chicken CD4+CD25+ cells. J Immunol 2011, 186:1997-2002.

16. Degen WGJ, Daal NV, Rothwell L, Kaiser P, Schijns VEJC: Th1/Th2 polarization by viral and helminth infection in birds. Vet Microbiol 2005, 105:163-167.

17. Göbel TW, Schneider K, Schaerer B, Mejri I, Puehler F, Weigend S, Staeheli P, Kaspers B: IL-18 stimulates the proliferation and IFN-gamma release of CD4+ T cells in the chicken: conservation of a Th1-like system in a nonmammalian species. J Immunol 2003, 171:1809-1815.

18. González-Navajas JM, Fine S, Law J, Datta SK, Nguyen KP, Yu M, Corr M, Katakura K, Eckman L, Lee J, Raz E: TLR4 signaling in effector CD4+ T cells regulates TCR activation and experimental colitis in mice. J Clin Invest 2010, 120:570-581.

19. Villanueva Al, Kulkarni RR, Sharif S: Synthetic double-stranded RNA oligonucleotides are immunostimulatory for chicken spleen cells. Dev Comp Immunol 2011, 35:28-34.

20. Karpala AJ, Lowenthal JW, Bean AG: Activation of the TLR3 pathway regulates IFNbeta production in chickens. Dev Comp Immunol 2008, 32:435-444.

21. Lian L, Ciraci C, Chang G, Hu J, Lamont SJ: NLRC5 knockdown in chicken macrophages alters response to LPS and poly (I:C) stimulation. BMC Vet Res 2012, 8:23.

22. Landrigan A, Wong MT, Utz PJ: CpG and non-CpG oligodeoxynucleotides directly costimulate mouse and human CD4+ T cells through a TLR9- and MyD88-independent mechanism. J Immunol 2011, 187:3033-3043.

23. Benatar T, lacampo S, Tkalec L, Ratcliffe MJ: Expression of immunoglobulin genes in the avian embryo bone marrow revealed by retroviral transformation. Eur J Immunol 1991, 21:2529-2536.

24. Pfaffl MW: A new mathematical model for relative quantification in real-time RT-PCR. Nucleic Acids Res 2001, 29:e45.

25. Pfaffl MW, Horgan GW, Dempfle L: Relative expression software tool (REST) for group-wise comparison and statistical analysis of relative expression results in real-time PCR. Nucleic Acids Res 2002, 30:e36.

\section{doi:10.1186/1756-0500-5-616}

Cite this article as: St. Paul et al.: Toll-like receptor ligands induce the expression of interferon-gamma and interleukin-17 in chicken CD4+ T cells. BMC Research Notes 2012 5:616.

\section{Submit your next manuscript to BioMed Central and take full advantage of:}

- Convenient online submission

- Thorough peer review

- No space constraints or color figure charges

- Immediate publication on acceptance

- Inclusion in PubMed, CAS, Scopus and Google Scholar

- Research which is freely available for redistribution 